\title{
STOCK MARKET REACTIONS ON RETURNS AND TRADING VOLUME: THE IMPACT OF THE GLOBAL FINANCIAL CRISIS ${ }^{1}$
}

\author{
Asiya Sohail \\ Lecturer, COMSATS Institute of Information Technology, Islamabad. \\ asiya@vcomsats.edu.pk \\ Mobeen Ur Rehman ${ }^{2}$ \\ PhD candidate at Shaheed Zulfikar Ali Bhutto Institute of Science and Technology (SZABIST), Islamabad. \\ mobeenrehman@live.com

\section{Atiya Yasmin Javid} \\ Professor, Pakistan Institute of Development Economics, Islamabad. \\ attiyajavid@pide.org.pk
}

\begin{abstract}
Objective: This study empirically examines the short term under- and overreaction effect in the Karachi Stock Exchange, Pakistan, in the context of the 2008 Global Financial Crisis considering the period from September 2007 to 2009.

Background: Investors' probable reaction to an anticipated or unforeseen event is gaining immense importance in order to understand the complex market behavior. The arrival of good or bad news can tend to bring about a rise or decline in the stock price even if the news does not directly impact company's performance.

Method: The sample data for the stock price, trading volume and KSE 100 index are obtained from the Karachi Stock Exchange (KSE) and Securities and Exchange Commission of Pakistan (SECP) websites for the period September 2007 to 2009. To reach our objective, we used event studies.

Results: There is evidence of significant overreaction in the first two weeks and significant underreaction in the 12th and 24th week following specifically in the financial sector. For the non-financial sector, the returns stay positive and insignificant for both the winner and loser portfolios thereby negating any evidence of significant overreaction.

Contributions: We wants to contribute to the existing literature, testing the under- and overreaction hypothesis in an emerging market. Our study also attempts to draw attention to any evidence of returns reversal in the loser and winner portfolios based on the trading volume. Investors may capitalize on the trading volume information to earn contrarian profits.
\end{abstract}

Keywords: Underreaction; Overreaction; Efficient Market Hypothesis; Event Study; Return Reversals.

\footnotetext{
${ }^{1}$ Received: 11/07/2016. Revised: 09/12/2016. Accepted: 09/12/2016 by Luiz Felipe de Araújo Pontes Girão (Adjunct Editor). Published: 01/01/2017. University: UFPB.

${ }^{2}$ Address: Kehkashan, SZABIST 90، Scheme 5, 75600, Karachi, Pakistan.

DOI: http://dx.doi.org/10.18405/recfin20170108
} 


\section{INTRODUCTION}

Investors' probable reaction to an anticipated or unforeseen event is gaining immense importance in order to understand the complex market behavior. The arrival of good or bad news can tend to bring about a rise or decline in the stock price even if the news does not directly impact company's performance. Such fluctuations in the prices signify certain anomalies that help to understand the irrational behavior of the investors. Therefore, among other possibilities, the market may overall exhibit under reaction or overreaction - a phenomenon that is attributed to the inconsistent investor behavior, which can be associated with events like the international financial crisis. This study attempts to analyze the presence of any such under and overreaction in the short term, in order to better understand the impact and magnitude of 2008 financial crisis, on the Pakistani stock market. It is expected that there was not any severe impact of 2008 crisis on the local economy due to its limited international linkages.

The association between stock prices and new information arrival has led towards the development of hypotheses based on the behavioral aspects of investor decision making. For example, the heuristic of anchoring proposes that people often relate themselves to some specific elements or conditions of reference in order to make decisions conveniently. Brown, Harlow, and Tinic (1988) developed the uncertain information hypothesis, which predicted that the stock prices would rise after extreme stock price change. Investors' strong response to unfavorable or favorable information has been postulated by the overreaction hypothesis according to which, investors temporarily price securities below (above) their new intrinsic values on the release of unfavorable (favorable) news as they tend to be under the influence of the heuristic of representativeness.

On the other hand, the under reaction hypothesis postulates that investors do not respond strongly enough to unfavorable and favorable information which can be linked to the heuristic of conservatism. Barberis, Shleifer, and Vishny (1998), hereinafter BSV, argue that once the investors form beliefs they may become reluctant to change the prior and may tend to under weigh the arrival of new information. Their theory assumes that prices are driven by a single representative agent and that agent exhibits the cognitive biases of conservatism and representativeness.

Keynes (1964) made the earliest observation about overreaction in the capital markets by arguing that the ephemeral and nonsignificant daily fluctuations in the profits of existing investments actually create an altogether excessive, and even an absurd, influence on the market. Similarly, Williams (1956) has noted that prices are based too little on long-term dividend paying power and too much on current earning power. Moreover, Kahneman and Tversky (1982) typified the excessive reaction to current information which seemed to characterize all the securities and futures markets in a precise way.

With more frequent financial crisis on the rise, it would be interesting to understand and analyze the impact of the global financial crisis of 2008 on the local economy which is categorized as an emerging economy. Any trend in the trading behavior may be identified during the 2008 global financial crisis at Karachi Stock Exchange, which is major stock market of Pakistan. This also allows to test if the trading patterns of a semi-strong form of efficient market prevails in the times of international financial crisis or not.

Thus, the first objective of the current study is to establish whether investors at KSE exhibited any under- or overreaction in the stock market as an aftermath of the global financial crisis of 2008. It tries to examine the short term under- and overreaction by using daily stock returns data of Karachi Stock Exchange over the period of September 2007 to 2009. It will also help to assess the shock absorbing capability of the local market in terms of under or over-reaction in the financial and nonfinancial sectors. Second objective of current study is to examine the effect of variations in the trading volumes of stocks on investor's under and over reaction. 
Besides contributing to the existing literature in testing the under- and overreaction hypothesis in an emerging market, the study also attempts to draw attention to any evidence of returns reversal in the loser and winner portfolios based on the trading volume. The investors may capitalize on the trading volume information to earn contrarian profits.

The remainder of the study is organized as follows. Section two reviews the relevant theoretical and empirical literature in the area of investor reaction to news. The third section deals with sample selection, data and methodological framework. The empirical findings and discussion of results are presented in section four. The last section provides conclusion and implications of study.

\section{REVIEW OF RELATED LITERATURE}

A major area of research on stock markets focuses on testing for the validity of the Efficient Market Hypothesis (EMH), i.e., testing whether the price of a security fully and rapidly reflects the available information about the stock. Prior studies had the main aim of determining whether price movements are predictable and exhibit any recognizable pattern.

As surveyed by Fama (1970), stocks tend to follow random walk and thus fail to indicate any specific pattern. The financial markets have become increasingly volatile and unstable worldwide. Shiller (1981) says that this excessive volatility is caused because the stocks are more volatile as comapred to what the fundamentals require. Lo and MacKinlay (1990) find that excessive volatility violates random walk, so, there may be a human element adding to volatility.

The finance researchers generally consider these phenomena as market efficiency anomalies. Among these so-called market efficiency anomalies is the issue of stock market under- and overreaction which involves individual investors' psychology in the decision-making process. The combined effect is that investors tend to either underreact or overreact to unexpected new information. They are likely to underbid or overbid a firm's stock and then later reverse themselves. Researchers believe that this phenomenon is especially evident for significant and negative events (Lo \& MacKinlay, 1990).

There has been evidence of market under- or overreaction in past studies. Barberis, Shleifer, and Vishny (1998) argue that under the influence of conservatism, investors tend to underweight the arrival of new evidence when updating their beliefs, so their past beliefs tend to persist. They highlight that the investment decisions are the result of two prominent psychological biases: representativeness and conservatism. According to them representativeness can generate the "long-term reversals" and "value premium" patterns. Supposing that a firm posts a few quarters of surprisingly good earnings growth., if it suffers from representativeness, investors will be too quick to believe that the firm's long-term earnings growth is high. They will therefore bid the firm's stock price up too much, giving the stock a high $\mathrm{P} / \mathrm{E}$ ratio. And given their overly high expectations, investors will, on average, be disappointed by the firm's subsequent earnings growth. On average, then, the stock's subsequent performance will be poor. The authors claim providing an explanation for why a stock with a high $\mathrm{P} / \mathrm{E}$ ratio generally earns a low return later on also explaining the value premium puzzle. Representativeness says that people are sometimes too quick to draw inferences from data.

But psychologists have also found that, in some circumstances, people can be too slow to draw inferences from data i.e. they sometimes pay too little attention to the data and stick too much to their prior views. This evidence is sometimes given the label "conservatism". The authors also note that conservatism can generate the "momentum" and "post earnings announcement drift" patterns in the data. Supposing that a firm that is thought of having moderate future earnings growth, then the firm surprisingly announces good earnings and if the investor suffers from conservatism, its prospects are nothing special for him and this is not to change his mind. 
Daniel, Hirshleifer, and Subramanyam (1998) explained event-related security price anomalies according to the cognitive biases of investor overconfidence and self-attribution. They have analyzed the effect of overconfident traders in market under reaction and overreaction based on two well-known psychological biases: investor overconfidence about the precision of private information; and biased self-attribution, which causes asymmetric shifts in investors' confidence as a function of their investment outcomes. They show that overconfidence implies negative long-lag autocorrelations, excess volatility, and, when managerial actions are correlated with stock mispricing, public-event-based return predictability. Biased self-attribution adds positive short-lag autocorrelations (momentum), short-run earnings (drift) but negative correlation between future returns and long-term past stock market and accounting performance. Their theory also offers several untested implications and implications for corporate financial policy.

Hong and Stein (1999) which constructs equilibrium model with under-reaction and momentum. The authors suggest that gradual diffusion of news causes momentum, and feedback traders who buy based on past returns create overreaction because they attribute the actions of past momentum traders to news and hence end up purchasing too much stock, which, when positions are reversed, causes momentum

Williams (1956) has noted that the prices are less based on long-term dividend paying power and more on current earning power. Moreover, Kahneman and Tversky (1982) typified the excessive reaction to current information which seemed to characterize all securities and futures markets in a precise way. DeBondt and Thaler (1985) have found that the extreme winner's stocks subsequently underperformed the market while the extreme loser's stocks subsequently outperformed the market. DeBondt and Thaler (1987) have reexamined investor overreaction through controlling for firm size and variance in systematic risk and provided evidence that supported the overreaction hypothesis. They also get results in favor of the overreaction hypothesis for the January affect that give unusual returns in January.

Providing support for these hypotheses, the results of Bremer and Sweeney (1991) have confirmed the overreaction hypothesis by examining the losers' portfolio only. Their results are consistent with the efficient markets hypothesis when a three-day event window is considered for the post-event returns associated with New York Stock Exchange (NYSE) securities, but when a twentyday event window is considered, the returns are consistent with the under reaction hypothesis. Howe (1986) finds overreaction in the short run but under reaction in the long run for his sample of losers. However, there is overreaction in both the short run and the long run for his sample of winners. The overreaction phenomenon over the short run and long run was also analyzed by Brown and Harlow (1988). Their evidence has supported the overreaction hypothesis in the short run and the under reaction hypothesis in the long run just like Howe (1986).

Further analysis that supported the uncertain information hypothesis for losers and winners is provided by Brown, Harlow, and Tinic (1988). Several factors, including the underlying information causing the initial stock price movements may have attributed to the disparity of results among these studies. Evaluating weekly returns, Lo and MacKinlay (1990) have found that less than $50 \%$ of the profits are generated by the stock market overreaction. Moreover, the authors have suggested that contrarian profits might not be solely driven by stock market overreaction and presented the lead lag effect as a primary contributor. However, Jegadesh and Titman (1995) do not support this view about contrarian profits and their generation by the lead lag effect. According to them only overreaction of stock prices could be attributed to firm-specific information especially announcement of profits. Providing further support, Da, Liu and Schaumburg (2010) confirm that it is due to the arrival of firm-specific news on discount rate as well as liquidity shocks.

The under- reaction and overreaction hypothesis is also investigated in some of the international markets, which are Spain (Alonso \& Rubio, 1990), Canada (Kryzanowsky \& Zhang, 1992), 
Australia (Brailsford, 1992), UK (Clare \& Thomas, 1995), Japan (Chang et al. (1995)), Hong Kong (Akhigbe et al. 1998)), Brazil (DaCosta \& Newton, 1994), Richards (1997), New Zealand (Bowman \& Iverson, 1998), China (Wang et al., 2004), Greece (Antoniou et. al., 2005) and London (Spyrou et.al., 2007).

The market reactions i.e. under- and overreaction have often been associated with the trading volume of a particular stock in the past. Moskowitz and Grinblatt (1999) revealed that return reversals and return continuation are highly firm-specific. They emphasized that firm size contains significant information about probable future returns.

Bremer and Hiraki (1999) established that the loser stocks with high trading volume tend to have larger return reversals. Overreaction is investigated in the high and low volume stocks of NYSE and AMEX by Cooper (1999) whose study has provided results in favor of overreaction.

Conrad (1994) later found that stronger reversals were observed in case of low volume stocks as compared to high volume stocks. Similar results are revealed for the Australian market by Lee et al (2003), emphasizing that the high volume stocks have significantly lower returns as compared to the low volume stocks.

Iihara et al (2004) evidenced in their study that the return reversals are more pronounced in case of loser stocks as compared to winner stocks.

Kang, Liu and Ni (2002) witnessed short-term contrarian returns for the Chinese stock market, Chou, Wei and Chung (2007) for the Tokyo stock exchange based on one-month formation and holding periods from 1 to 24 months. Griffin, Kelly and Nardari (2010) conclude that the emerging markets incorporate past market and portfolio returns into prices slightly better than the developed markets.

Arifin and Power (1996) and Ali, Ahmed and Anusakumar (2011) have considered the Malaysian stock market for their respective studies. Afrin and Power (1996) results have indicated the existence of return reversals as the winner stocks exhibit negative returns for weeks one to three, and the loser stocks yield positive returns throughout the ten weeks. Ahmad and Tjan (2004) have claimed that over reaction existed in Malaysian Stock Exchange and find that winner and loser stocks experienced return reversals.

However, there are negative and insignificant returns for the loser minus winner portfolios. As stipulated by De Bondt and Thaler (1985), to justify the presence of overreaction. Ali, Nassir, Hassan and Abidin (2010) results are over all inconclusive for Malaysia with evidence of overreaction for some events e.g., political events but not for others, like international events. Contrarily, Hameed and Ting (2000) find that the high volume stocks performed much better in terms of price returns as compared to the low trading volume stocks. Their study is based on the stocks listed on Kuala Lumpur Stock Exchange. A positive relationship between trading volume and contrarian profits is found by McInish et al (2008), supporting that the reversals were higher for high volume stocks for Hong Kong, Malaysia and Japan.

In order to test for under- and overreaction in the financial and non-financial sectors, the excess returns are compared between winner and loser portfolios and on the basis of trading volume (high, medium and low trading stocks) the following hypotheses are formulated:

H1: Investors either under-weighed or over- weighed the crisis news in the in the Financial and non-Financial Sector

H2: Investors under-weighed or over- weighed the financial crisis news in the high, medium and low trading volume stocks

H3: The level of returns of the Winner stocks is equal to the level of returns of the Loser stocks in the period following the financial crisis. 


\section{DATA AND METHODOLOGY}

\subsection{Data}

The sample data for the stock price, trading volume and KSE 100 index are obtained from the Karachi Stock Exchange (KSE) and Securities and Exchange Commission of Pakistan (SECP) websites for the period September 2007 to 2009. This data is used to obtain the daily and weekly returns of an individual stock. The first week's returns prior to the event date are considered for the creation of the winner and loser portfolios. The companies selected for the study are listed on the KSE 100 Index. Two main sectors namely financial (Commercial Banks) and non-financial (Oil \& Gas and Chemicals) sectors are chosen for analysis.

\subsection{Methodology}

The initial task of conducting an event study is to define the event of interest and identify the period over which the security prices of the firms involved in this event will be examined - the event window. For example, if one is looking at the information content of an earnings with daily data, the event will be the earnings announcement and the event window will include the one day of the announcement. It is customary to define the event window to be larger than the specific period of interest. This permits an examination of periods surrounding the event.

In practice, the period of interest is often expanded to multiple days, including at least the day of the announcement and the day after the announcement. This captures the price effects of announcements which occur after the stock market closes on the announcement day. The periods prior to and after the event may also be of interest. For example, in the earnings announcement case, the market may acquire information about the earnings prior to the actual announcement and one can investigate this possibility by examining pre-event returns.

MacKinlay (1997) prescribes that the appraisal of the event's impact requires a measure of the abnormal return. The abnormal return is the actual ex post return of the security over the event window minus the normal return of the firm over the event window. The normal return is defined as the expected return without conditioning on the event taking place.

For firm $i$ and event date $\tau$ the abnormal return is as described in equation 1 .

$$
\mathrm{ARi} \tau=\operatorname{Ri} \tau-\mathrm{E}(\operatorname{Ri} \mid \mathrm{X} \tau)
$$

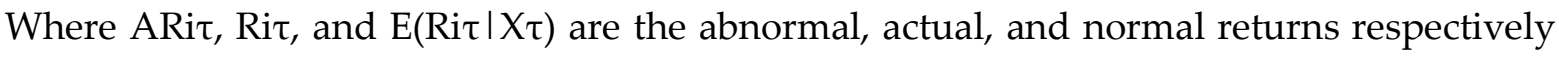
for time period $\tau$. $X \tau$ is the conditioning information for the normal return model.

There are two common choices for modeling the normal return - the constant mean return model where $X \tau$ is a constant, and the market model where $X \tau$ is the market return. The constant mean return model, as the name implies, assumes that the mean return of a given security is constant through time. The market model assumes a stable linear relation between the market return and the security return.

MacKinlay (1997) and Campbell, Lo, and MacKinlay (1997) document the origins and breadth of event studies. Cross-sectional tests are a standard part of almost every event study. They are relevant even when the mean stock price effect of an event is zero. In addition, they are applicable regardless of horizon length. They are simple to do, but as discussed below, "one must be careful in interpreting the results" (Campbell, Lo \& Mackinlay, 1997).

The event study methodology is used to see the speed of adjustment of prices and trading volume to any new information. The cumulative performance of stocks is averaged over time considering the time before and after the event in line with the methodology adopted by MacKinlay (1997). 
Barberis, Shleifer and Vishny's (1998) has made use of the historical data to show that stocks with certain characteristics for example, stocks with low price-to-earnings ratios, or stocks with good performance over the past six months tend to perform particularly well. They argue that these patterns arise because some investors exhibit psychological biases in their thinking - specifically, two biases known as representativeness and conservatism. In order to conduct the analysis why certain kinds of stocks have better performance on average than certain other kinds of stocks, they have used cross-section of average stock returns. Their research presents one of the first "behavioral" models of the cross-section to argue that several facts about the cross-section may reflect less than fully rational thinking on the part of some investors. Two other well-known behavioral models of the cross-section are those of Daniel, Hirshleifer, and Subrahmanyam (1998) and Hong and Stein (1999).

To investigate the investor overreaction at the KSE the same event window methodology has been used as employed by Ali et al (2011) and Spyros et al (2007). The event date under consideration is 15th September 2008 (Lehman Brothers' demise). A pre event window is created based on 250 days prior to the event for the portfolio formation (Top Gainers and Losers). The post event window under consideration stretched to 1, 2, 3, 4, 12, 24, 36 and 52 weeks.

In the first part of the study, the winner and loser portfolios are constructed for the KSE listed companies similar to the method used by lihara et al. (2004). First, the stocks are ranked according to the past week's return. Then the top and bottom one third of the stocks are used for portfolio construction rather than deciles or quintiles due to the smaller number of stocks compared to studies in other markets. The top one third is classified as winner stocks and the bottom one third are classified as loser stocks. Equally weighted winner and loser portfolios are then constructed using these selected stocks. The portfolios are held for the following $H$ weeks, where $H$ takes the value 1, 2, 3, 4 , $12,24,36$ or 52 . The portfolio returns are calculated accordingly to assess whether there is any overreaction. Under the overreaction hypothesis, the Average Cumulative Abnormal Return (ACAR) of the loser minus winner portfolio should be greater than zero when overreaction is present. While, according to the under reaction hypothesis, the ACAR of the loser minus winner portfolio should be less than zero to indicate any presence of under reaction.

The top one third is classified as winner stocks and the bottom one third are classified as loser stocks. Equally weighted winner and loser portfolios are then constructed using these selected stocks. The portfolios are held for the following $H$ weeks, where $H$ takes the value 1, 2, 3, 4, 12, 24, 36 or 52 . The portfolio returns are calculated accordingly to assess whether there is any overreaction.

Under- the overreaction hypothesis, the Average Cumulative Abnormal Return (ACAR) of the loser minus winner portfolio should be greater than zero when overreaction is present. While, according to the under reaction hypothesis, the ACAR of the loser minus winner portfolio should be less than zero to indicate any presence of under reaction. In the second part of the study, the stocks are categorized on the basis of the trading volume at the end of the previous year. In order to address the element of size, the turnover ratio is used as proxy for the trading volume. The turnover ratio is the trading volume divided by the number of outstanding shares at the end of the previous year.

Based on the turnover ratio, the stocks are classified as high, medium and low volume stocks. As a next step each volume category is further grouped as winner and loser stocks and the overreaction or under reaction is tested by the differential value of their ACARs. The level of returns and the extent of reversal is also compared among the various volume categories.

In order to measure the impact of the event, the actual return and the expected returns are used. The observed return is calculated from each company's historical return by taking the log first difference of the closing price of each stock and KSE 100 index. The expected returns are estimated by the Risk Adjusted Market model given below. 


$$
\mathrm{R}_{\mathrm{it}}=\alpha_{\mathrm{i}}+\beta_{\mathrm{i}} \mathrm{R}_{\mathrm{mt}}+\varepsilon_{\mathrm{it}} \text {, where } \mathrm{E}\left(\mathrm{R}_{\mathrm{it}}\right)=\alpha_{\mathrm{i}}+\beta_{\mathrm{i}} \mathrm{R}_{\mathrm{mt}}
$$

$\mathrm{E}(\mathrm{Rit})=$ Expected Return of security $\mathrm{i}$ at day $\mathrm{t}, \mathrm{Rmt}=$ Market Return at day $\mathrm{t}, \alpha \mathrm{i}=$ Intercept of the regression, $\beta \mathrm{i}=$ Beta of the market, $\varepsilon i t=$ Error Term. The difference between the observed return Rit and the expected return $\mathrm{E}$ (Rit)is then used to compute the abnormal returns ARit for firm i with event date $t$.

$$
\mathrm{AR}_{\mathrm{it}}=\mathrm{R}_{\mathrm{it}}-\mathrm{E}\left(\mathrm{R}_{\mathrm{it}}\right)
$$

The Cumulative Abnormal Return (CAR) is then computed by summing the abnormal returns for stock i from $t_{1}$ time to $t_{2}$.

$$
\mathrm{CAR}_{(t i 1, t i 2)}=\sum_{\mathrm{t}=\mathrm{t} 1}^{\mathrm{t} 2} \mathrm{AR}_{i t}
$$

CARs are calculated over the next $\mathrm{H}$ weeks indicating the various holding periods (where $\mathrm{H}$ takes the value $1,2,3,4,12,24,36$, or 52). Finally, the average cumulative abnormal return (ACARpt) is computed for the winner and loser stock portfolios as follows:

$$
\operatorname{ACAR}_{\mathrm{pt}}=\frac{1}{\mathrm{~N}} \Sigma_{\mathrm{i}=1}^{\mathrm{N}} \mathrm{CAR}_{(\mathrm{ti} 1, \mathrm{ti} 2)}
$$

The ACAR for the arbitrage portfolio considers the difference between the loser and winner stock portfolios (i.e., $\mathrm{ACAR}_{\text {loser }}-\mathrm{ACAR}_{\text {winner) }}$ ). As dictated by the overreaction hypothesis, if there is significant return for the arbitrage portfolio $\left(A C A R_{\text {loser }}-A C A R_{\text {winner }}>0\right)$, then overreaction is present in the market. On the other hand if there are no significant returns and then there is indication of under-reaction portfolio (ACARloser $\left.-\mathrm{ACAR}_{\text {winner }}<0\right)$ For the efficient markets, the Efficient Market Hypothesis $(\mathrm{EMH})$ implies that the difference should be zero $\left(A C A R_{\text {loser }}-A C A R_{\text {winner }}=0\right)$. To test the significance of ACAR results, the two-sided t-test is used.

\section{EMPIRICAL RESULTS AND DISCUSSION}

\subsection{Summary Statistics of Data}

The sample includes in all 36 stocks with 18 stocks from the Commercial Banking sector representing the financial sector while 9 stocks each from the Oil \& Gas and Chemicals sector represent the non-financial sector. In all, 106 weeks are considered based on 52 pre-event and 54 post-event weeks with a formation period and various holding periods following the crisis. The descriptive statistics for the entire sample are presented in the following table in terms of the weekly returns and abnormal returns. 
Table 4.1 - Descriptive Statistics for the total sample (\%)

\begin{tabular}{|c|c|c|c|c|c|c|c|}
\hline & Mean & $\begin{array}{l}\text { Standard } \\
\text { Deviation }\end{array}$ & Kurtosis & Skewness & Minimum & Maximum & Sum \\
\hline $\begin{array}{l}\text { Average Weekly Re- } \\
\text { turns (All Sectors) }\end{array}$ & 0.0083 & 0.136 & 306.73 & 17.30 & -0.08 & 2.42 & 2.69 \\
\hline $\begin{array}{ll}\text { Abnormal } & \text { Returns } \\
\text { (All Sectors) } & \end{array}$ & 0.0094 & 0.173 & 120.20 & 8.93 & -0.60 & 2.42 & 3.04 \\
\hline \multicolumn{8}{|l|}{ Financial Sector } \\
\hline Winners & -0.0014 & 0.018 & 8.60 & -1.56 & -0.08 & 0.05 & -0.08 \\
\hline Losers & -0.0011 & 0.018 & 1.47 & -0.47 & -0.05 & 0.04 & -0.06 \\
\hline \multicolumn{8}{|l|}{ Non-Financial Sector } \\
\hline Winners & -0.0002 & 0.014 & 1.90 & -0.40 & -0.05 & 0.03 & -0.01 \\
\hline Loser & 0.0016 & 0.019 & 2.26 & -0.89 & -0.06 & 0.04 & 0.09 \\
\hline
\end{tabular}

There are 376 weekly observations for the entire sample with 515 working days. Overall, an average return of 0.0083 and standard deviation of 0.136 is observed for the weekly return. Similarly, the abnormal returns exhibit an average of 0.0094 and standard deviation of 0.173 . The returns are positively skewed with a minimum average return of -0.08 and minimum abnormal return of -0.60 . In the financial sector, the mean returns are negative with a deviation of 0.018 . In the non-financial sector, the winner stocks have negative average returns of -0.0002 while the loser stocks show positive returns of 0.0016 . The returns are negatively skewed both for the winner and loser portfolios of both financial and non-financial sectors.

Table 4.2 presents the results for weekly average cumulative abnormal returns of the winner, loser, and loser-winner portfolios during the formation and various holding periods from $t=-250$ to $t=+260$ in the pre- and post-crisis period. Portfolio for the winner (loser) is assembled choosing the best (worst) performing stocks on the basis of the previous one week return. Whereas, the portfolio returns are calculated for the $\mathrm{H}$ holding periods. The column titled 'formation period' presents the portfolio abnormal returns for the week $t-52$. The other columns provide the average cumulative abnormal returns (ACAR) for 8 holding periods ranging from 1 to 52 weeks. The associated $t$-statistic for the sample is mentioned in the braces. 
Table 4.2 - ACAR (\%) for Winner, Loser and Loser-Winner Portfolios for the Financial Sector

\begin{tabular}{|c|c|c|c|c|c|c|c|c|c|}
\hline \multirow[b]{2}{*}{ PORTFOLIO } & \multicolumn{2}{|c|}{ FORMATION } & \multicolumn{6}{|c|}{ HOLDING PERIOD (WEEKS) } & \multirow[b]{2}{*}{52} \\
\hline & PERIOD & 1 & 2 & 3 & 4 & 12 & 24 & 36 & \\
\hline Winner & 0.06 & -0.04 & -0.04 & -0.01 & -0.01 & 0.06 & 0.07 & 0.04 & -0.01 \\
\hline t-stat & $(-4.35) *$ & $(-1.31)$ & $(-1.15)$ & $(-0.37)$ & $(-0.30)$ & $(1.98)^{*}$ & $(2.33) *$ & $(1.40)$ & $(-0.20)$ \\
\hline Loser & -0.21 & 0.01 & 0.01 & 0.01 & 0.005 & -0.005 & -0.01 & -0.005 & 0.002 \\
\hline t-stat & $(-4.32) *$ & $(0.69)$ & $(0.84)$ & $(0.30)$ & $(0.27)$ & $(-0.27)$ & $(-0.42)$ & $(-0.26)$ & $(0.14)$ \\
\hline $\begin{array}{l}\text { Loser-Win- } \\
\text { ner }\end{array}$ & -0.27 & 0.05 & 0.05 & 0.02 & 0.01 & -0.06 & -0.08 & -0.05 & 0.01 \\
\hline t-stat & $(-0.09)$ & $(1.96)$ * & $(1.99)$ * & $(0.67)$ & $(0.57)$ & $(-2.15) *$ & $(-2.76) *$ & $(-1.66)$ & $(0.33)$ \\
\hline
\end{tabular}

* Statistical Significance at the 5\% level Table .4.2 presents the Average Cumulative Abnormal Return (ACAR) and the tstatistic for the Winner, Loser and Loser-Winner portfolios. KSE 100 Index is used as a proxy for the market return.

Comparison between the formation and holding period returns reveal prominent reversals especially for loser portfolios. For the formation period, the winner stocks have a significantly positive return of 0.06 which turns into insignificant negative returns for the next four holding periods indicating return reversals. This is followed by significant positive returns in the 12th and 24thweeki.e $0.06 \%$ and $0.07 \&$ at five percent level of significance.

On the other hand, the loser stocks exhibit significantly negative returns followed by positive but insignificant returns for the next four holding periods indicating some level of reversals. The loser portfolio returns indicate absence of any significant return reversals for all the 52 weeks following the crisis news. There is evidence of overreaction for the next four weeks out of which the first two weeks show significant overreaction with $0.05 \%$ ACAR at the five percent level of significance.

The next two holding periods i.e. 12th and 24th weeks indicate negative but significant ACAR of $-0.06 \%$ and $-0.08 \%$ respectively which signifies the presence of under reaction in the financial sector following the crisis news. Overall, there are disproportionate levels of reversal for both the winner and loser portfolios. The reversals extend up to 4 weeks for the both the portfolios, but weaken for holding periods exceeding 4 weeks. This implies that the return reversals for the winner and loser stocks are more severe in time period immediately following the crisis news and later on it fades out. Bremer \& Hiraki (1999) have also observed such reversals in the winner and loser portfolios' returns.

The results of the study can also be related to those of Khaneman and Tversky (1982) in which individual investor are found to focus more on unexpected bad news rather than good news. It seems from the study that investors have a propensity to overestimate the possible effects of negative news than the positive news in the stock market.

Table 4.2 also sheds light on the differences in ACAR among the loser and winner for the various holding periods supporting under reaction hypothesis for a negative ACAR and overreaction for positive ACAR. The result indicates presence of significant overreaction in the first two weeks with ACAR of $0.05 \%$ at $5 \%$ level of significance. Similarly, there is evidence of under reaction in the 12 th and 24 th week with ACAR of $-0.06 \%$ and $-0.08 \%$ at $5 \%$ significance level. Overall, the results present strong evidence in support of both under and overreaction for the financial sector stocks. From these findings it could be incurred that particularly for the financial sector stocks, if the arbitrage portfolio is held for 4 weeks or less then the contrarian strategy could be profitable. 
The findings of the study are consistent with that of Griffin, Kelly and Nardari (2010) who suggest that the emerging markets do not under or overreact to news contained in the past returns any more than in developed markets. It is concluded that the emerging markets incorporate past market and portfolio returns into prices slightly better than the developed markets.

The results are also in line with the study of Mohd, Arifin and Power (1996) that discovered significant overreaction only for the week 1 and week 2 . In any case, the findings broadly corroborate the findings of the earlier study in that overreaction is present in KSE 100 Index (Ali, Ahmed \& Anusakumar, 2011; Ahmad \& Tjan, 2004), where the loser minus winner portfolio do not yield any positive returns and their study is conducted only for the year 1997. The results are consistent with those of Mohd, Arifin and Power (1996).

The average weekly cumulative abnormal returns from $t=-250$ and $t=+260$ for the losers and winners of the non-financial sector are presented in Table 4.3.

Table 4.3 - ACAR (\%) for Winner, Loser and Loser-Winner Portfolios for the Non-Financial Sector

\begin{tabular}{|c|c|c|c|c|c|c|c|c|c|}
\hline \multirow[b]{2}{*}{ PORTFOLIO } & \multirow{2}{*}{$\begin{array}{l}\text { FORMATION } \\
\text { PERIOD } \\
\end{array}$} & \multicolumn{8}{|c|}{ HOLDING PERIOD (WEEKS) } \\
\hline & & 1 & 2 & 3 & 4 & 12 & 24 & 36 & 52 \\
\hline $\begin{array}{l}\text { Winner } \\
\text { t-stat }\end{array}$ & $\begin{array}{l}0.20 \\
(4.04) *\end{array}$ & $\begin{array}{l}0.0020 \\
(0.26)\end{array}$ & $\begin{array}{l}0.0052 \\
(0.67)\end{array}$ & $\begin{array}{l}0.0047 \\
(0.60)\end{array}$ & $\begin{array}{l}0.0050 \\
(0.64)\end{array}$ & $\begin{array}{l}0.0067 \\
(0.85)\end{array}$ & $\begin{array}{l}0.0064 \\
(0.82)\end{array}$ & $\begin{array}{l}0.0064 \\
(0.82)\end{array}$ & $\begin{array}{l}0.0057 \\
(0.73)\end{array}$ \\
\hline Loser & 0.92 & 0.003 & 0.004 & 0.002 & 0.002 & 0.004 & 0.004 & 0.005 & 0.003 \\
\hline t-stat & $(0.06)$ & (1.09) & $(1.52)$ & $(0.79)$ & $(0.71)$ & $(1.51)$ & $(1.33)$ & $(1.68)$ & $(1.04)$ \\
\hline Loser - Winner & 0.72 & 0.001 & -0.001 & -0.003 & -0.003 & -0.003 & -0.003 & -0.002 & -0.003 \\
\hline t-stat & $(-3.98) *$ & $(\mathbf{0 . 8 3})$ & $(\mathbf{0 . 8 5})$ & $(0.19)$ & $(0.08)$ & $(0.66)$ & $(0.51)$ & $(0.86)$ & $(\mathbf{0 . 3 1})$ \\
\hline
\end{tabular}

* Statistical Significance at the $5 \%$ level

For the non-financial sector, comparison between the formation and holding period returns do not reveal any prominent reversals for either of the portfolios. For the formation period, only the winner stocks had significant positive returns. During the holding period, the ACAR remains positive and insignificant not only for the winner stocks but also for the loser stocks. For the winner portfolio, there is a strong positively significant return in week $t-52$ (at the $5 \%$ level), and displays similar positive returns up to week 52 which are statistically insignificant.

However, a gradually increasing positive trend in returns can be observed for holding periods of 12 weeks. Similarly, there are notable positive returns through all the weeks. Overall, there are no signs of any reversals for the winner and loser portfolios.

Overall, the results of this study present strong evidence in support of absence of under or overreaction for the winner and loser portfolio. These results endorse the findings of Ahmad and Tjan (2004), where the loser minus winner portfolio does not yield any significant returns.

In the second part of the study, the overreaction hypothesis is tested in the KSE 100 index companies by establishing a relationship between the market reactions and the stock trading volume. By employing the turnover ratio, the sample is categorized into high, medium and low volume stocks.

Further in each category the winner and loser stocks are identified based on their returns and the overreaction hypothesis is tested. Table4.4 reveals the average cumulative abnormal returns (ACAR) for the formation and eight holding periods for the three volume categories.

For the high-volume stocks, comparison between the formation and holding period returns does not reveal any prominent reversals. For the formation period, the winner stocks have a negative 
and insignificant ACAR of $-0.006 \%$. The winner portfolio exhibits insignificant negative returns for the 1st, 4th, 12th, 24th, 36th and 52nd holding periods.

Insignificant return reversal is observed in the 2nd and 3rd with an ACAR of $0.001 \%$ and $0.0001 \%$. In case of the loser portfolio, the returns are negative and insignificant for the formation period and also for the 1 st holding period with an ACAR of $-0.015 \%$ and $-0.005 \%$ respectively. Positive and insignificant returns are found in the rest of the holding periods till week 52 . This indicates presence of insignificant return reversal following the crisis news. The ACAR differential of loser and winner portfolio has a negative and insignificant value of $-0.009 \%$ for the formation period.

The ACAR remains negative in the 1st holding period with a value of $-0.004 \%$ indicating insignificant under reaction. There is some evidence of overreaction in the rest of the holding periods however it is found to be statistically insignificant. Although insignificant, there is indication of higher returns in case of the loser stocks in the post-crisis period for the high trading volume stocks.

The stocks with medium level of trading volume majorly indicate insignificant overreaction. The winner stocks exhibit a positive but significant ACAR of $0.03 \%$ for the formation period. In the first holding period the trend remains the same but from the 2nd to the 52nd holding period a negative ACAR is observed indicating presence of return reversal but insignificant.

On the other hand, the loser stocks of this volume category have a positively insignificant ACAR of $0.014 \%$ in the formation period which is followed by a negatively insignificant ACAR of $0.001 \%$ in the first holding period. Positive and insignificant returns are observed through the rest of the holding periods till week 52 .

Overall, the ACAR differential of the loser and winner portfolios indicates insignificant levels of under reaction in the 1st holding period and overreaction in the rest of the weeks. The level of returns is higher for the loser stock in comparison with the winner stocks. The winner stocks majorly report negative returns while the loser stocks exhibit although insignificant but positive returns.

The winner portfolio of the low-volume stocks shows an insignificant negative ACAR of $0.004 \%$ for the formation period. In the first two holding periods return reversal is seen with ACAR value of $0.002 \%$ and $0.001 \%$. This reversal tends to be insignificant.

Later, in the 3rd and 4th holding periods negative and significant ACAR is evidenced with values of $-0.022 \%$ and $-0.036 \%$ respectively. For the rest of the holding periods the ACAR stays negative but is insignificant in nature. The loser stocks also exhibit a negative and insignificant ACAR for the formation period with a value of $-0.005 \%$. For the holding periods of 1, 12, 24, 36 and 52 the returns are negative but insignificant. Weeks 2, 3 and 4 show positive but insignificant returns. The ACAR differential of the loser and winner stocks provides evidence of significant overreaction in the 3rd and 4th holding period in the low volume category.

The reaction is persistent in the rest of the weeks too but it is found to be statistically insignificant. Also, the returns are observed to be slightly lower for the winner portfolio as compared to the loser portfolio. 
Table 4.4: ACAR (\%) for the High, Medium and Low Volume Stocks

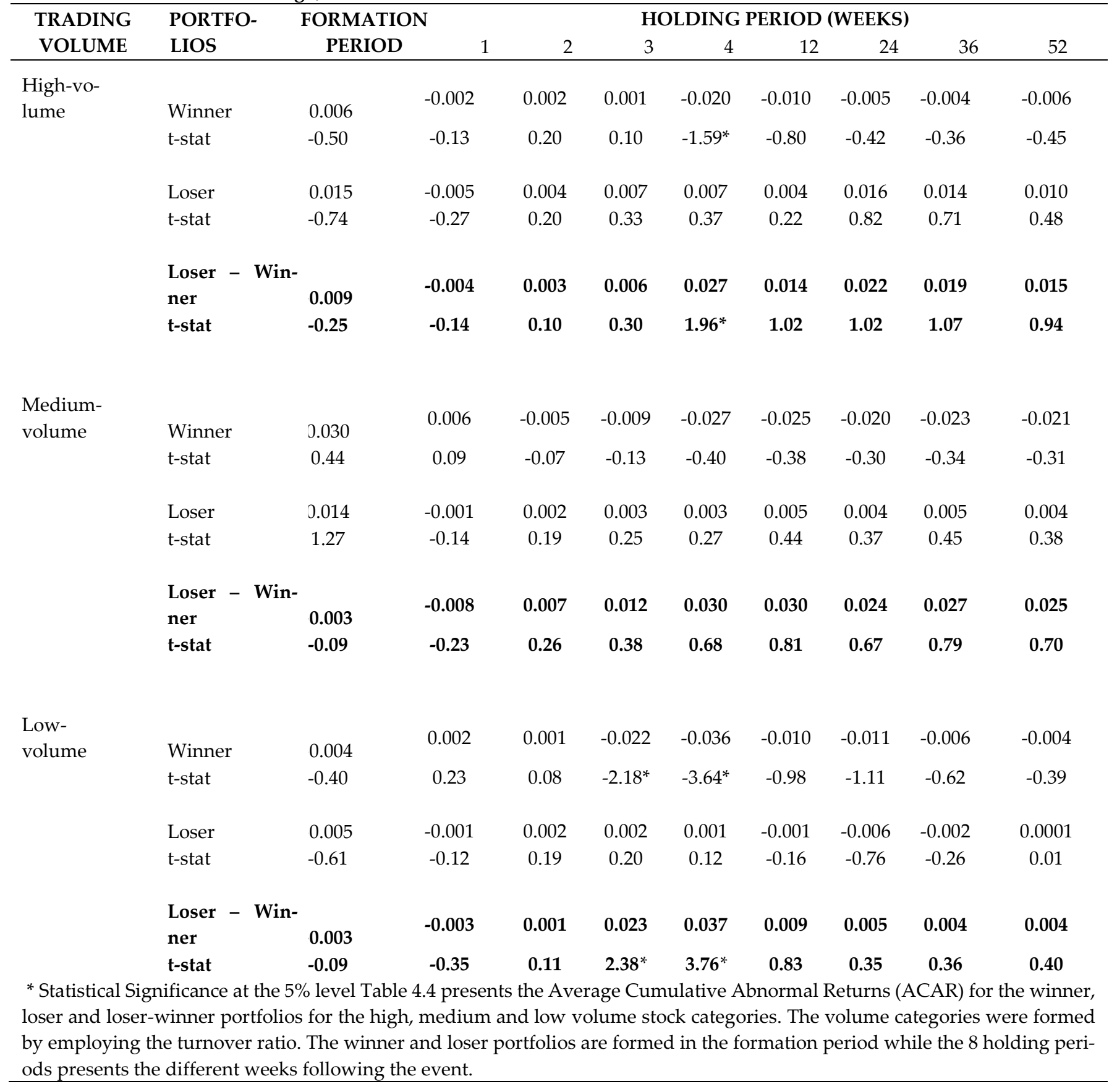

From the findings it could be inferred that overreaction is more evident in case of low-volume stocks as compared to the medium- or high volume stocks. Although overreaction is seen in the medium and high- volume stocks but it is found to be statistically insignificant. There is indication of insignificant under reaction in the first week following the portfolio formation in all of the three volume categories which diminishes in the second week post-crisis.

The winner stocks mostly show negative returns in all the volume categories indicating return reversal of insignificant nature. On the other hand, the loser portfolio mostly exhibits positive returns in the high, medium and low-volume categories. 


\section{CONCLUSION AND PRACTICAL IMPLICATIONS}

\subsection{Conclusion}

The purpose of this study was to analyze the investor behavior in terms of overreaction to better understand the impact of the global financial crisis of Year 2008 on the Pakistani stock market, which is considered among the emerging Asian economies. The study helps to analyze the shock absorbing capability of the local market in terms of investor overreaction.

Overall, the results presented strong evidence in support of both under and overreaction for the financial sector while for the non-financial sector there are not any pronounced reversals for the post-crisis period which indicates a diminished degree of any reaction after the crisis period which may be attributable to the cautionary behavior of investors. The level of returns of the Winner stocks is not equal to the level of returns of the Loser stocks in the period following the financial crisis

The findings from the stocks trading volume reveals that the low-volume stocks tend to overreact significantly in the post-crisis period. This is evidenced by the significant return reversals especially in the third and fourth weeks following the news. The results are in line with the findings of Ali et al (2011), Iehara et al (2004) and Lee et al (2003). The loser stocks of same category yield positive returns while the winner stocks exhibit negative but insignificant returns highlighting reversals.

It is concluded that the overreaction is statistically significant in the third and fourth weeks following the portfolio formation compared to the medium or high-volume stocks. Also, the returns are mostly positive for the loser portfolio and they are negative for the winner portfolio in the high, medium and low trading volume categories indicating return reversals. It could be inferred from the findings that in the case of Pakistan, the financial sector has limited linkages with the global financial market as there is less financial liberalization and financial innovation.

The absence of a well-developed financial market especially the secondary market averted Pakistan from the direct impact of the financial or banking crisis at large. Thus, it is concluded that Pakistan remained well-insulated against the contagion in the international financial markets.

\subsection{Implications of the Study}

The aim of the present study is to explore the investor behavior in relation to the under and overreaction as a result of the global financial crisis of the year 2008. The present study is helpful to the local institutional as well as individual investors. As the institutional investors are considered to be the notable participants and key players of any stock market due to their large holdings of shares of companies, the findings of the present study will be of great advantage to the institutional investors in administering and devising a safe and secure investment strategy, especially, in times of global financial crisis in the future. The study may also be helpful to the institutional investors in realizing the importance of any global event in the future.

Besides their focus on the domestic events such as local interest rates, T-bill rates, terrorism attacks, etc., they need to be aware of the global happenings in order to better align their investment objectives with the global events to minimize the risk of their investments. As these individual investors are also the important players of the stock markets, the results of the study can also be helpful to them in adhering to the buy and hold strategy to minimize risk and to avoid any losses.

The present findings may also prove to be advantageous for the Securities and Exchange Commission of Pakistan (SECP) in devising policy to control the volatility in the stock markets of Pakistan. It has been observed in the data period under study that after September 15, 2008which is a referral point for the global financial crisis; the stock trading was temporarily closed in Pakistan.

Thus, the SECP may use the results of the study to devise a mechanism which shall help absorb the effects of global financial events / crises in the future. In lei of this the trading in the stock 
markets may not need to be temporarily terminated and eventually this will build investor's confidence and reduce volatility in the stock markets. Also, the trading volume information can be capitalized by the investors to adopt any profitable contrarian strategy while forming investment portfolios especially following a crisis news by buying loser stocks and selling winner stocks.

Additionally, the results of the study may be valuable for the different sectors of the Pakistan economy as the data for three sectors i.e. Banking, Oil and Gas, and Chemicals is analyzed to assess the impact of this particular global event. Also, the management of these economic sectors may seek guidance from the results of the present study in formulating various strategies for the returns associated with their stocks by helping the companies retain their shareholders in the long run.

\section{REFERENCES}

Ahmad, Z., \& Tjan, S. (2004). Short-run overreaction, stock prices and investors' irrationality in the Kuala Lumpur Stock Exchange. International Journal of Management Studies, 11, 1-19.

Akhigbe, A., Gosnell, T. \& Harikumar, T. (1998). Winners and losers on NYSE: A reexamination using daily closing bid-ask spreads. Journal of Financial Research, 21, 53- 64.

Ali, N., Nassir, A. M., Hassan, T., \& Abidin, S. Z. (2010). Short run stock overreaction: Evidence from Bursa Malaysia. International Journal of Economics and Management, 4, 319-333.

Ali, R., Ahmad, Z. \& Anusakumar, S. V. (2011). Stock Market Overreaction and Trading Volume: Evidence from Malaysia. Asian Academy of Management Journal of Accounting and Finance. Vol. 7, pp 103.-119.

Alonso, A. \& Rubio, G. (1990). Over reaction in the Spanish equity market. Journal of Banking and Finance, 14, 469-48.

Antoniou, A., Galariotis, E. C. \& Spyrou, S.I. (2005). Contrarian profits and the overreaction hypothesis: The case of the Athens Stock Exchange. European Financial Management, 11, 71-98.

Barberis, N. C., Shleifer, \& Vishny, R. W. (1998). A model of investor sentiment, Journal of Financial Economics 49, 307-343.

Binder, J. (1998). The Event Study Methodology Since 1969. Review of Quantitative Finance and Accounting, Vol. 11

Brailsford, T. (1992). A test for the winner-loser anomaly in the Australian equity market: 1958-1987. Journal of Business Finance and Accounting, 19, 225-241.

Bremer, M. \& R. J. Sweeney (1991). The reversal of large stock price decreases, Journal of Finance 46, 747-54.

Bremer, M., \& Hiraki, T. (1999). Volume and individual security returns on the Tokyo Stock Exchange. Pacific-Basin Finance Journal, 7, 351-370. 
Brown, K. C., W. V. Harlow \& S. M. Tinic (1988). Risk aversion: Uncertain information and market efficiency. Journal of Financial Economics Vol. 22, pp.355-85.

Brown, K. C. \& W. V. Harlow (1988). Market overreaction: Magnitude and intensity, Journal of PortfolioManagement14, 6-13.

Bowman, R.G. \& Iverson, D. (1998). Short-run over-reaction in the New Zealand stock market. Pacific-Basin Finance Journal 6, 475-491.

Campbell, J.Y., Lo, A.W. \& A.W. MacKinlay. 1997. The Econometrics of Financial Markets. Princeton University Press (Princeton, New Jersey).

Chang, R., McLeavey, D. \& Rhee, S. (1995). Short-term abnormal returns of the contrarian strategy in the Japanese stock market. Journal of Business Finance and Accounting, 22, 1035-1048.

Chou, R. (1988) Volatility persistence and Stock Market Valuation: The empirical evidence using GARCH, Journal of Applied Econometrics, 56(3) 701-714.

Chou, P. H., Wei, K. C., \& Chung, H. (2007). Sources of contrarian profits in the Japanese stock market. Journal of Empirical Finance, 14, 261-286.

Claessens S. S. Djankov, J. Fans \& L. Lang (1996). The Benefits and Costs of Internal Markets, Evidence from Asian Financial Crisis. Unpublished working Paper, World Bank.

Clare, A. \& Thomas, S. (1995). The overreaction hypothesis and the UK stock market. Journal of Business Finance and Accounting, 22, 961-973.

Conrad, J., \& G. Kaul (1988). Time Variation in Expected Returns, Journal of Business, Vol. 61, pp. 409425.

Conrad, J. S., Hameed, A., \& Niden, C. (1994). Volume and autocovariances in short-horizon individual security returns. Journal of Finance, 49, 1035-1329.

Cooper, M. (1999). Filter rules based on price and volume in individual security overreaction. Review of Financial Studies, 12, 901-935.

Cox, D. R. \& D. R. Peterson (1994). Stock returns following large one-day declines: Evidence on shortterm reversals and longer-term performance, Journal of Finance 49, 255-67.

DaCosta Jr., N.C.A., (1994). Overreaction in the Brazilian stock market. Journal of Banking and Finance, $18,633-642$.

Da, Z., Liu, Q., \& Schaumburg, E. (2010). Decomposing short-term return reversal (SSRN Working paper). Retrieved from http://ssrn.com/abstract=1551025. 
De Bondt, F.M. \&Thaler, R. (1985). Does the stock market overreact? Journal of Finance, Vol. 40, pp. 793-805.

DeBondt, W. F. M. \& R. H. Thaler, (1987). Further evidence on investor overreaction and stock market seasonality, Journal of Finance Vol. 42, pp. 557-80.

Fama, E. (1970). Efficient capital markets: a review of theory and empirical work. Journal of Finance, Vol. 25, pp. 383-417.

Fama, E. F. (1991). Efficient Capital Markets: II. Journal of Finance, Vol. 46, pp. 1575-1617.

Fama, E.F., Fisher, L., Jensen, M.C. \& R. Roll (1969). The adjustment of stock prices to new information. International Economic Review 10(1), 1-21.

Griffin, J. M., Kelly, P. J., \& Nardari, F. (2010). Do market efficiency measures yield correct inferences? A comparison of developed and emerging markets. Review of Financial Studies, 23(8), 32253277.

Moskowitz, T.J., Grinblatt, M., (1999). Do industries explain momentum? Journal of Finance 54, 12491290.

Hameed, A., \& Ting, S. (2000). Trading volume and short-horizon contrarian profits: evidence from the Malaysian market. Pacific-Basin Finance Journal, 8(1), 67-84.

Howe, J. S., (1986). Evidence on stock market overreaction, Financial Analysts Journal 42, 74-77.

Iihara, Y., Kato, H. K., \& Tokunaga, T. (2004). The winner-loser effect in Japanese stock returns. Japan and the World Economy, 16, 471-485.

Jegadeesh, N., \& Titman, S. (1993). Returns to buying winners and selling losers: Implications for stock market efficiency. Journal of Finance, 48, 65-91.

Jegadeesh, N., \& Titman, S. (1995). Overreaction, delayed reaction, and contrarian profits. Review of Financial Studies, 8, 973-993.

Javid, Y. Attiya (2009). The Response of the Pakistani Stock market to a Cataclysmic Event. MPRA Paper No. 37565. Retrieved from http://mpra.ub.uni-muenchen.de/37565/ on 01.05.2013.

Javid, Y. Attiya \& Ayaz Ahmed (1999) The Response of Karachi Stock Exchange to Nuclear Detonations. The Pakistan Development Review, 38(4).778-786.

Jensen, M. C. \& Richard S. Ruback (1983). The Market for Comparative Control: The Scientific Evidence. Journal of Financial Economics, 11(1-4), 5-50. 
Jong Frank De A. Kemmna \& T. Klock (1992). The Contribution to Event Study Methodology with an Application to the Dutch Market, Journal of Banking and Finance, 16, 11-36.

Kang, J., Liu, M.-H., \& Ni, S. X. (2002). Contrarian and momentum strategies in the China stock market: 1993-2000. Pacific-Basin Finance Journal, 10(3), 243-265.

Kahneman, D., \&Tversky, A. (1982). The simulation heuristic, In D. Kahneman, P. Slovic, \& A. Tversky (eds). Judgement under uncertainty: Heuristics and biases (pp. 201-208). New York: Cambridge University Press.

Keynes, J. M. (1936). The General Theory of Employment, Interest and Money, Macmillan, London.

Keynes, J. M. (1964). The General Theory of Employment, Interest and Money, New York: Harcourt, Brace, Jovanovich.

Khotari, S.P. \& J.B. Warner (2005). Econometrics of event studies. Chapter 1 in Handbook of Corporate Finance: Empirical Corporate Finance, B. EspenEckbo (ed.), Elsevier/North Holland.

Kotz, David (2008). Contradictions of Economic Growth in the Neoliberal Era. Review of Radical Political Economy, Vol. 40, No. 2.

Kryzanowski, L. \& Zhang, H. (1992). The contrarian strategy does not work in Canadian markets. Journal of Financial and Quantitative Analysis, 27, 383-395.

Kutan, A. M., Muradoglu, G., \& Sudjana, B. G. IMF programs, financial and real sector performance, and the Asian crisis. Journal of Banking \& Finance. 2012, 36(1): 164-182.

Lee, D. D., Chan, H., Faff, R. W., \& Kalev, P. S. (2003). Short-term contrarian investing is it profitable? Yes and no. Journal of Multinational Financial Management, 13, 385-404.

Lo, A. W. \& C. MacKinlay (1988). Stock Market Prices Do Not Follow Random Walks: Evidence from a Simple Specification Test. Review of Financial Studies, Vol.1, 41-66.

Lo, A., \& MacKinlay, C. (1990). When are contrarian profits due to stock market overreaction? Review of Financial Studies, 3(2), 175-206.

Lobe, S., \& Rieks, J. (2011). Short-term market overreaction on the Frankfurt stock exchange. The Quarterly Review of Economics and Finance, 51(2), 113-123.

Lockton, D (2012). Cognitive biases, heuristics and decision-making in design for behavior change', working paper, available at http://danlockton.co.uk

MacKinlay, A.C. (1997). Event studies in economics and finance. Journal of Economic Literature 35(1), 13-39. 
McInish, T. H., Ding, D. K., Pyun, C. S., \& Wongchoti, U. (2008). Short-horizon contrarian and momentum strategies in Asian markets: An integrated analysis. International Review of Financial Analysis, 17, 312-329.

McQueen C. \& R. Vance (1993). Stock Prices, News and Business Conditions. Review of Financial Studies, 6(3).683-707.

MohdArifin, N., \& Power, D. M. (1996). Some evidence of short-run market overreaction for the Kuala Lumpur Stock Exchange. Capital Market Review, 4, 21-32.

Myers, S. C. \& N. S. Majluf (1984). Corporate Financing and Investment Decisions When Firms have Information That Investor do not have. Journal of Financial Economics, 13(2).87-221.

Redelmeier, D. A. (2005). The cognitive psychology of missed diagnoses. Annals of Internal Medicine, Vol. 142, pp. 115-120.

Richards, A. (1997). Winner-loser reversals in national stock market indices: Can they be explained? Journal of Finance, 52, 2129-2144.

Ritter, Jay R. (2003). Behavioral Finance. Pacific-Basin Finance Journal. Vol. 11, No. 4, pp. 429-437.

Shah, Anuj K. \& Oppenheimer, Daniel M. (2008). Heuristics Made Easy: An Effort-Reduction Framework, Psychological Bulletin, Vol. 134, No. 2, pp. 207-222.

Shelor, R. M, D. C. Anderson and M. L. Cross (1992). Gaining from Loss: Property-Liability Insurance Stock Values in the Aftermath of 1989 California Earthquake. The Journal of Risk and Insurance. 59(3), 476-488.

Shiller, R. J. (1981). Do Stock Prices Move Too Much to be Justified by Subsequent Changes in Dividends. American Economic Review, 71: 421435.

Shiller, R. (2003). From Efficient Markets Theory to Behavioral Finance, Journal of Economic Perspectives, Vol.17, pp.83-104.

Siddiqui, Kalim (2008a). India's Obsession with Economic Growth. (in Norwegian), Klassekampen, 26th August, (pp 8-9), Oslo, Norway.

Siddiqui, Kalim (2008b). Recent Global Financial Crisis. (in Norwegian), Klassekampen, 20th October (pp. 16), Oslo, Norway.

Siddiqui, Kalim (2009). The Political Economy of Growth in China and India. Journal of Asian Public Policy (JAPP), March Vol.1, No.2, pp.17-35.

Spyros, S., Kassimatis, K. \& Galariotis, E. (2007). Short term overreaction, under reaction and efficient reaction: Evidence from the London Stock Exchange. Applied Financial Economics, 17, 221-235. 
Strong N, (1992), Modelling abnormal return: a review article, Journal of Business, Financing $\mathcal{E}$ Accounting, Vol. 09.

Tversky, A. \& D. Kahneman (1974). Judgement under uncertainty: heuristics and biases, Science, Vol. 185, pp. 1124-1131.

Wade, Robert (1998). The Asian Debt and Development Crisis of 1997.World Development, Vol.26, No.8, pp.1535-1553.

Wang, J., Burton, B. M., \& Power, D. M. (2004). Analysis of the overreaction effect in the Chinese stock market. Applied Economics Letters, 11(7), 437-442.

Williams, J. B., (1956). The Theory of Investment Value. North Holland. Amsterdam. 